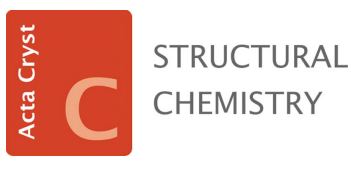

ISSN 2053-2296

\section{Hawley's Condensed Chemical Dictionary. Sixteenth Edition. By M. D. Larrañaga, R. J. Lewis Sr \& R. A. Lewis. Wiley, 2016. Hardback, Pp. XIII+1547. Price GBP 96.78. ISBN 9781118135150.}

\author{
Marc Hebrant* \\ Université de Lorraine, LCPME, UMR 7564, Villiers-lès-Nancy, F-54601, France, and CNRS, LCPME, UMR 7564, \\ Villiers-lès-Nancy, F-54601, France. *Correspondence e-mail: marc.hebrant@univ-lorraine.fr
}

Keywords: book review; chemical dictionary; Hawley

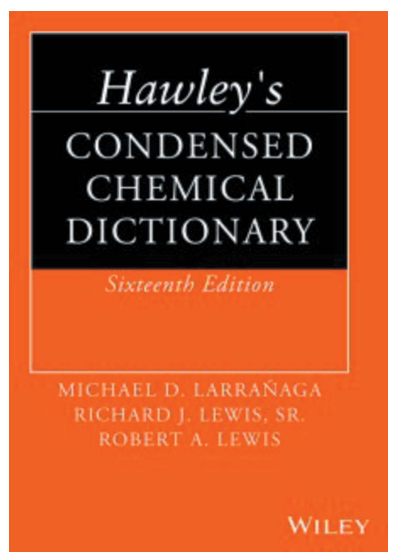

C 2016 International Union of Crystallography

The first question which arises when considering such a book is: who in 2016 is still using a dictionary instead of an internet search engine? Beginning my review, I had no clear answer to this question, but, since it is an impressive book (more than 1500 pages), and since it was on my desk, I decided to give it a chance.

I began to search systematically for the chemical words I encountered in my teaching and research work. I have been impressed by the quality of the definitions given and by the number of words present in this dictionary. I then decided to explore the content of the dictionary for compounds, i.e. their commercial names (e.g. Ludox $\left.{ }^{\mathbb{R}}\right)$, trade names, acronyms (e.g. RDGE) or 'official' names. Again, the number of entries of these types present in the book is very extensive and the information is very consisely presented. I have also been convinced by the definitions of fundamentals, basic concepts (solids and colloids, for instance), processes (e.g. the viscose process) and chemical reactivity rules (e.g. Saytzeff rule). The names of great chemists, as well as Nobel Prize winners, are also included.

Although, this dictionary is not a classical handbook of chemistry and physics, nor is it a Merck ${ }^{\circledR}$ Index, it does give some properties and CAS numbers of some compounds, as well as some chemical formulae, indications of toxicity and medicinal values.

When comparing the results obtained using the dictionary with those obtained from an internet search, in all cases the definitions I found in this book were, if not the only one, then by far the most pertinent. After two months of intensive use and hundreds of searches in the dictionary, very few words (only three in fact) and acronyms were found to be missing: 'TEMPO' (CAS 2564-83-2), RAFT for 'Reversible Addition Fragmentation chain Transfer' and, quite astonishingly, 'ionic liquid'. Considering the huge amount of work the dictionary represents (it is almost unbelievable that there are only three coauthors), it is very good value for money.

Clearly, I consider that this dictionary is a very valuable tool for all those who work in the various fields of chemistry or in multidisciplinary research. Masters or PhD students beginning in a new field will appreciate this data bank for handling a literature survey.

In my opinion, a copy should be owned by every research team and be present in the library of each institution providing Bachelor and Masters degrees in chemistry and related sciences. 